\title{
Prevalence of Neurodevelopmental Disorders in Japanese Children's Homes
}

\author{
Eiji Ozawa1', Kayo Takahashi², Susumu Harizuka ${ }^{3}$ \\ ${ }^{1}$ Faculty of Human-Environment Studies, Kyushu University, Fukuoka, Japan \\ ${ }^{2}$ Graduate School of Clinical Psychology, Kagoshima University, Kagoshima, Japan \\ ${ }^{3}$ Faculty of Human Sciences, Chikushi Jogakuen University, Fukuoka, Japan \\ Email: eiji@hes.kyushu-u.ac.jp
}

How to cite this paper: Ozawa, E., Takahashi, K., \& Harizuka, S. (2018). Prevalence of Neurodevelopmental Disorders in Japanese Children's Homes. Psychology, 9, 911-924.

https://doi.org/10.4236/psych.2018.95056

Received: January 13, 2018

Accepted: May 7, 2018

Published: May 10, 2018

Copyright (C) 2018 by authors and Scientific Research Publishing Inc. This work is licensed under the Creative Commons Attribution International License (CC BY 4.0).

http://creativecommons.org/licenses/by/4.0/

\section{Open Access}

\begin{abstract}
This study examined the prevalence of neurodevelopmental disorders among children receiving residential care in Japanese children's homes (CHs). The data on 7854 children aged 18 years or younger were collected using a questionnaire for psychotherapists worked at $174 \mathrm{CHs}$ in all regions of Japan. That included items of diagnostic state and experience of maltreatment. The prevalence of neurodevelopmental disorders was $24 \%$ in CHs. The most common type in CHs was intellectual disabilities (11.9\%), and the next most was autism spectrum disorder (6.1\%). Logistic regression models revealed the children with experience of maltreatment had high risk of autism spectrum disorder, attention deficit hyperactivity disorder, and specific learning disorder. These findings implied differential pattern from previous studies of Western countries.
\end{abstract}

\section{Keywords}

Neurodevelopmental Disorder, Residential Care, Children's Home, Out-of-Home Care, Child Maltreatment

\section{Introduction}

To establish an effective child protection and care system is an important task for all nations. The Japanese Ministry of Health, Labor, and Welfare (MHLW) (2016) reported that the number of child maltreatment consultations at child guidance centers in 2015 was 88,931 , and has been constantly increasing every year. Almost 46,000 children are in out-of-home care, and of those, 27,828 are in children's homes (CHs) as of the end of March 2015. CH is a residential institution for out-of-home care children, and admitted more than $60 \%$ of out-of-home 
care children in Japan. In Western countries, residential institution in child care system is mainly used for children with mental health problems or other special needs rather than foster care and adoption (Barth, 2005; Courtney, Dolev, \& Gillian, 2009). In Japan, contrary to this, $\mathrm{CHs}$ are selected as primary care form and generally used even with less-troubled children.

Prior research has suggested that children in child welfare services have high rates of mental health problems. A meta-analysis found that $49 \%$ of children in child welfare services have mental disorders, and this rate is nearly 4 times more than the general population (Bronsard et al., 2016). Developmental researchers claimed that out-of-home care for children has the negative effects on cognitive and neurodevelopmental difficulties particularly (Berger, Bruch, Johnson, James, \& Rubin, 2009; Pollak et al., 2010). An official Japanese survey also mentions that $28.5 \%$ of children in $\mathrm{CHs}$ have mental or physical disorders (Equal Employment, Children and Families Bureau, 2015). In this survey, the most common group of mental disorders is neurodevelopmental disorders: $12.3 \%$ have Intellectual Disabilities (ID), 5.3\% Pervasive Developmental Disorder (PDD), 4.6\% Attention Deficit Hyperactivity Disorder (ADHD), 1.2\% Specific Learning Disorders (SLD). This survey reported the total ratios in Japanese CHs, but the analysis of predictors and developmental features were lacking.

A large body of research has found the relationship between intellectual development and group residential care for children. Recently, the randomized control research in Romanian children (Fox, Almas, Degnan, Nelson, \& Zeanah, 2011) reported children in institutional care showed continuously lower IQs than typically raised children during 30 months to 8 years old. In a large meta-analysis from 19 different countries data, van Ijzendoorn, Luijk, \& Juffer (2008) similarly proved delaying intellectual development in institutional children, additionally they found details from multiple moderators. Children under 4 years old showed lower IQ, but the effect size in older children was smaller. Moreover, there were distinctions among socioeconomic levels of countries; children in the countries with a high human development index showed smaller IQ delays than elsewhere. Japan is one of the developed countries, and Japanese residential care system is unique as mentioned above. Therefore, the distinct intellectual development patterns could be expected between children in Japanese $\mathrm{CHs}$ and other countries.

Excluding ID, studies of ADHD in out-of-home care have been the most common among neurodevelopmental disorders. ADHD prevalence has been reported between $7.4 \%$ to $20 \%$ in out-of-home children (Ford, Vostanis, Meltzer, \& Goodman, 2007; Lehmann, Havik, Havik, \& Heiervang, 2013; McCann, James, Wilson, \& Dunn, 1996; McMillen et al., 2005; Meltzer, Gatward, Corbin, Goodman, \& Ford, 2003), and in the studies focused on residential care settings, percentages ranged between 3.8\% to 22.4\% (Bronsard et al., 2011; Jozefiak et al., 2016; Meltzer et al., 2003; Schmid, Goldbeck, Nuetzel, \& Fegert, 2008). Studies about the prevalence of Autism Spectrum Disorder (ASD) are comparatively 
few. In England, Meltzer et al. (2003) found the rate of PDD as 9.3\% in residential care. Studies in Norway reported PDD prevalence as $4.3 \%$ in foster care (Lehmann et al., 2013). These studies indicate the prevalence of neurodevelopmental disorders in residential care children range very widely.

In addition, few analyses evaluating age differences of the prevalence are available. It is established that some neurodevelopmental disorders have developmental trajectory in the general population; ASD tends to have continuity from childhood to adolescence (McGovern \& Sigman, 2005), but ADHD prevalence decreased in adolescence (Costello, Mustillo, Erkanli, Keeler, \& Angold, 2003). In residential care children, emotional and behavioral problems have developmental change (Burns et al., 2004; Ohara \& Matsuura, 2016). Therefore, it is important to discuss the developmental trajectory of children with neurodevelopmental disorders, in addition to the gender differences a number of studies addressed.

The goal of this study was to clarify the prevalence of neurodevelopmental disorders, especially focused on ASD, ADHD, SLD, and ID that estimated common among children in Japanese CHs. Moreover, we analyzed the distribution of prevalence by gender, age group, and experience of maltreatment to improve the assessment and to review effective care.

\section{Methods}

\subsection{Study Sample and Procedure}

This study included children admitted to CHs in all regions of Japan, as of January 1st 2015. CHs are managed by social welfare cooperation or local authorities approved under the Japanese Child Welfare Act. This act also provides the child guidance centers (CGCs) with authority to protect children from any kind of risks and to make a plan of out-of-home care if necessary. All of the children in out-of-home care receive intervention from the CGCs first, and on that occasion, they are assessed by multidisciplinary professions: social workers, psychologists, physicians, and so on. Every child who is suspected of having neurodevelopmental disorders has an opportunity of diagnostic evaluation in child guidance centers. When it was decided that a child should be admitted to a $\mathrm{CH}$, his or her assessment report involving developmental history, psychosocial aspects, medical diagnosis, and other characteristics will be referred to the specific home simultaneously. In the case of children who show signs of neurodevelopmental disorders after being placed into care, $\mathrm{CHs}$ can request local CGCs to re-evaluate them, or to refer to another child psychiatry agency.

In CHs, childcare staff handle child rearing directly, and in addition, psychotherapists are assigned to implement psychological assessment and treatment for children. The psychotherapists mainly have a responsibility to utilize psychosocial and medical information from CDCs to customize care plans, and they are concurrently expected to recognize the slightest signs of any disorders from daily behaviors. On these grounds, we considered that the study conducting psycho- 
therapists as respondents could improve diagnostic reliability. Psychotherapists working at 600 Japanese CHs were invited to participate in this study in January to February in 2015. All study protocols were conducted in accordance with the ethical principles of the Declaration of Helsinki. We informed psychotherapists and superintendents of $\mathrm{CHs}$ about the goal, procedures, and corresponding address of this study with a survey questionnaire.

After excluding data from $\mathrm{CHs}$ which declined participation and had missing value, those from $174 \mathrm{CHs}$ were eligible, and the response rate was $29 \%$. Finally, the study sample included 7854 children, consisting of 4239 boys and 3615 girls.

\subsection{Diagnosis of Neurodevelopmental Disorders}

Diagnostic data were collected from a questionnaire reporting the number of children in their $\mathrm{CHs}$ for each neurodevelopmental disorder: ASD, ADHD, SLD, and ID. Classifications of neurodevelopmental disorders in this study were identified from DSM-5 (American Psychiatric Association, 2013). This latest edition of DSM was not yet common among Japanese professions during the period of data collection in early 2015 , because the official Japanese version was published in 2014. Therefore, short Japanese descriptions about diagnostic criteria of neurodevelopmental disorders according to DSM-5 was added to the questionnaire. In particular, the criteria of ASD were largely changed from previous edition, and hence it was specifically explained that ASD classification in this study were inclusive of autistic disorder, Asperger's disorder, or pervasive developmental disorder not otherwise specified, those were diagnosed under DSM-IV-TR (American Psychiatric Association, 2000).

The psychotherapists were asked to ascertain these diagnostic data from child records in their $\mathrm{CHs}$, and respond each number of children.

\subsection{Other Data Collection}

The questionnaire also included items about gender, age groups, and experiences of maltreatment with children in CHs. Age groups of children were chosen from 4 educational stages in Japan. The age groups primarily ranged as follows: 1) preschool grade as under 6 years, 2) elementary school grade as 7 to 12 years, 3) junior high school grade as 13 to 15 years, and 4) high school grade as 16 to 18 years. Experiences of maltreatment denoted the developmental history of child abuse and neglect prior to being protected by child guidance centers, and those determined from child records in their $\mathrm{CHs}$.

\subsection{Statistical Analyses}

Data were analyzed using the statistical programming language $\mathrm{R}$, version 3.3.2 (R Core Team, 2016). Descriptive statistics were examined to outline the sample characteristics. The prevalence of neurodevelopmental disorders was calculated with $95 \%$ confidence intervals (CI) around population using the Clopper-Pearson method. Gender and age group differences were estimated by chi-square tests. 
Logistic regression models were used to examine the factors associated with the diagnoses. Significance level of .05 were used for all statistical tests.

\section{Result}

\subsection{Characteristics of Study Sample}

Table 1 shows the descriptive statistics of the sample. Of the 7854 children, the age groups based on educational stages were follows: preschool (17\%), elementary school (37\%), junior high school (24\%), and high school (21\%). Almost $60 \%$ of children in $\mathrm{CHs}$ had experience of maltreatment. In total, 1861 children (24\%) had more than one diagnosis of neurodevelopmental disorders.

\subsection{Prevalence of Neurodevelopmental Disorders by Gender and Age Groups}

The numbers of children with each of the 4 types of neurodevelopmental disorders by gender and age groups are presented in Table 2 .

The overall ASD percentage was $6.10 \%, 95 \%$ CI $[5.58,6.65]$, and observed significant difference between gender, $\chi^{2}(1)=55.81, p<.001$, and age groups, $\chi^{2}$ (3) $=21.39, p<.001$. The elementary school boys showed the highest ratio of ASD: $9.20 \%, 95 \%$ CI $[7.83,10.72]$.

The ADHD prevalence among all samples was 4.97\%, 95\% CI [4.50, 5.47], and also group differences were significant: gender, $\chi^{2}(1)=87.99, p<.001$, and age group, $\chi^{2}(3)=76.37, p<.001$. The children with the highest ADHD prevalence were the junior high school boys: 9.74\%, 95\% CI [7.99, 11.74].

In the case of SLD, the total ratio was lower than other types, $0.81 \%, 95 \% \mathrm{CI}$ $[0.63,1.04]$. Gender difference of SLD was significant, $\chi^{2}(1)=7.61, p=.006$, although age group difference was a nonsignificant trend, $\chi^{2}(3)=7.68, p=.053$.

The prevalence of ID showed the highest ratio among neurodevelopmental disorders in this study, total $11.93 \%, 95 \%$ CI $[11.22,12.67]$. Chi-square analysis found difference within age groups, $\chi^{2}(3)=75.58, p<.001$, and without gender, $\chi^{2}(1)=1.37, p=.241$. Children with ID were major in the high school stage with both genders.

\subsection{Factors Associated with Neurodevelopmental Disorders}

The number and ratio of neurodevelopmental disorders by experience of child maltreatment appears in Table 3. Simple logistic regression models were carried out to examine the relationship between variables and the diagnostic status of neurodevelopmental disorders, and to produce the odds ratios (ORs). The explanatory variables were the experience of child maltreatment, gender, and age. To make it easier to compare ORs, elementary school grades that had the largest samples were used as the reference category in age groups. Table 4 shows the results.

The effect of child maltreatment was significant in all types of diagnoses. Three types of disorders had higher prevalence in children with experience of 
Table 1. Description of children in the study.

\begin{tabular}{|c|c|c|}
\hline & $\mathrm{n}$ & $\%$ \\
\hline Total N & 7854 & \\
\hline \multicolumn{3}{|l|}{ Gender } \\
\hline Male & 4239 & 54 \\
\hline Female & 3615 & 46 \\
\hline \multicolumn{3}{|l|}{ Age group } \\
\hline Preschool & 1353 & 17 \\
\hline Elementary school & 2926 & 37 \\
\hline Junior high school & 1909 & 24 \\
\hline High school & 1666 & 21 \\
\hline \multicolumn{3}{|c|}{ Experience of maltreatment } \\
\hline Yes & 4501 & 57 \\
\hline No & 3353 & 43 \\
\hline \multicolumn{3}{|c|}{ Status of neurodevelopmental disorders } \\
\hline No diagnosis & 5993 & 76 \\
\hline 1 diagnosis & 1705 & 22 \\
\hline 2 diagnoses & 147 & 1.9 \\
\hline 3 diagnoses & 9 & 0.1 \\
\hline
\end{tabular}

Table 2. Prevalence of neurodevelopmental disorders in Japanese children's home.

\begin{tabular}{|c|c|c|c|c|c|c|c|c|c|c|c|}
\hline & \multicolumn{3}{|c|}{ Total } & \multicolumn{3}{|c|}{ Male } & \multicolumn{3}{|c|}{ Female } & \multirow{2}{*}{\multicolumn{2}{|c|}{$\mathrm{p}$-value }} \\
\hline & $\mathrm{n}$ & $\%$ & $95 \% \mathrm{CI}$ & $\mathrm{n}$ & $\%$ & $95 \% \mathrm{CI}$ & $\mathrm{n}$ & $\%$ & $95 \mathrm{CI}$ & & \\
\hline \multicolumn{12}{|c|}{ Autism Spectrum Disorder } \\
\hline Total & 479 & 6.10 & {$[5.58,6.65]$} & 338 & 7.97 & {$[7.18,8.83]$} & 141 & 3.90 & {$[3.29,4.58]$} & $<.001$ & a \\
\hline \multicolumn{12}{|l|}{ Age group } \\
\hline Preschool & 46 & 3.40 & {$[2.50,4.51]$} & 32 & 4.41 & {$[3.04,6.17]$} & 14 & 2.23 & {$[1.22,3.71]$} & \multirow{4}{*}{$<.001$} & \\
\hline Elementary school & 201 & 6.87 & {$[5.98,7.85]$} & 148 & 9.20 & {$[7.83,10.72]$} & 53 & 4.02 & {$[3.03,5.23]$} & & \\
\hline Junior high school & 127 & 6.65 & {$[5.58,7.86]$} & 89 & 8.76 & {$[7.09,10.67]$} & 38 & 4.26 & {$[3.03,5.79]$} & & \\
\hline High school & 105 & 6.30 & {$[5.18,7.58]$} & 69 & 7.76 & {$[6.09,9.72]$} & 36 & 4.63 & {$[3.27,6.36]$} & & \\
\hline \multicolumn{12}{|c|}{ Attention Deficit Hyperactivity Disorder } \\
\hline Total & 390 & 4.97 & {$[4.50,5.47]$} & 301 & 7.10 & {$[6.35,7.92]$} & 89 & 2.46 & {$[1.98,3.02]$} & $<.001$ & a \\
\hline \multicolumn{12}{|l|}{ Age group } \\
\hline Preschool & 17 & 1.26 & {$[0.73,2.00]$} & 11 & 1.52 & {$[0.76,2.70]$} & 6 & 0.96 & {$[0.35,2.07]$} & \multirow{4}{*}{$<.001$} & \\
\hline Elementary school & 187 & 6.39 & {$[5.53,7.34]$} & 152 & 9.45 & {$[8.06,10.98]$} & 35 & 2.66 & {$[1.86,3.68]$} & & b \\
\hline Junior high school & 131 & 6.86 & {$[5.77,8.09]$} & 99 & 9.74 & {$[7.99,11.74]$} & 32 & 3.58 & {$[2.46,5.02]$} & & \\
\hline High school & 55 & 3.30 & {$[2.50,4.28]$} & 39 & 4.39 & {$[3.14,5.95]$} & 16 & 2.06 & {$[1.18,3.32]$} & & \\
\hline
\end{tabular}




\section{Continued}

\section{Specific Learning Disorder}

\begin{tabular}{|c|c|c|c|c|c|c|c|c|c|c|}
\hline Total & 64 & 0.81 & {$[0.63,1.04]$} & 46 & 1.09 & {$[0.80,1.44]$} & 18 & 0.50 & {$[0.30,0.79]$} & .006 \\
\hline \multicolumn{11}{|l|}{ Age group } \\
\hline Preschool & 3 & 0.22 & {$[0.05,0.65]$} & 3 & 0.41 & {$[0.09,1.20]$} & 0 & 0.00 & {$[0.00,0.48]$} & \multirow{4}{*}{.053} \\
\hline Elementary school & 26 & 0.89 & {$[0.58,1.30]$} & 20 & 1.24 & {$[0.76,1.91]$} & 6 & 0.46 & {$[0.17,0.99]$} & \\
\hline Junior high school & 17 & 0.89 & {$[0.52,1.42]$} & 12 & 1.18 & {$[0.61,2.05]$} & 5 & 0.56 & {$[0.18,1.30]$} & \\
\hline High school & 18 & 1.08 & {$[0.64,1.70]$} & 11 & 1.24 & {$[0.62,2.20]$} & 7 & 0.90 & {$[0.36,1.85]$} & \\
\hline \multicolumn{11}{|c|}{ Intellectual Disability } \\
\hline Total & 937 & 11.93 & {$[11.22,12.67]$} & 523 & 12.34 & {$[11.36,13.37]$} & 414 & 11.45 & {$[10.43,12.54]$} & .241 \\
\hline \multicolumn{11}{|l|}{ Age group } \\
\hline Preschool & 92 & 6.80 & {$[5.52,8.27]$} & 55 & 7.59 & {$[5.77,9.76]$} & 37 & 5.89 & {$[4.18,8.03]$} & \multirow{4}{*}{$<.001$} \\
\hline Elementary school & 317 & 10.83 & {$[9.73,12.02]$} & 176 & 10.94 & {$[9.45,12.57]$} & 141 & 10.71 & {$[9.09,12.50]$} & \\
\hline Junior high school & 250 & 13.10 & {$[11.61,14.69]$} & 135 & 13.29 & {$[11.26,15.53]$} & 115 & 12.88 & {$[10.75,15.25]$} & \\
\hline High school & 278 & 16.69 & {$[14.93,18.57]$} & 157 & 17.66 & {$[15.21,20.33]$} & 121 & 15.57 & {$[13.09,18.32]$} & \\
\hline
\end{tabular}

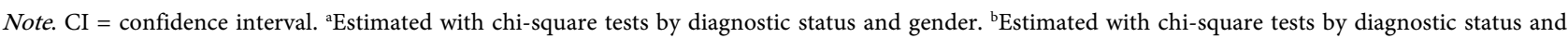
age groups.

Table 3. Prevalence of neurodevelopmental disorders by experience of maltreatment.

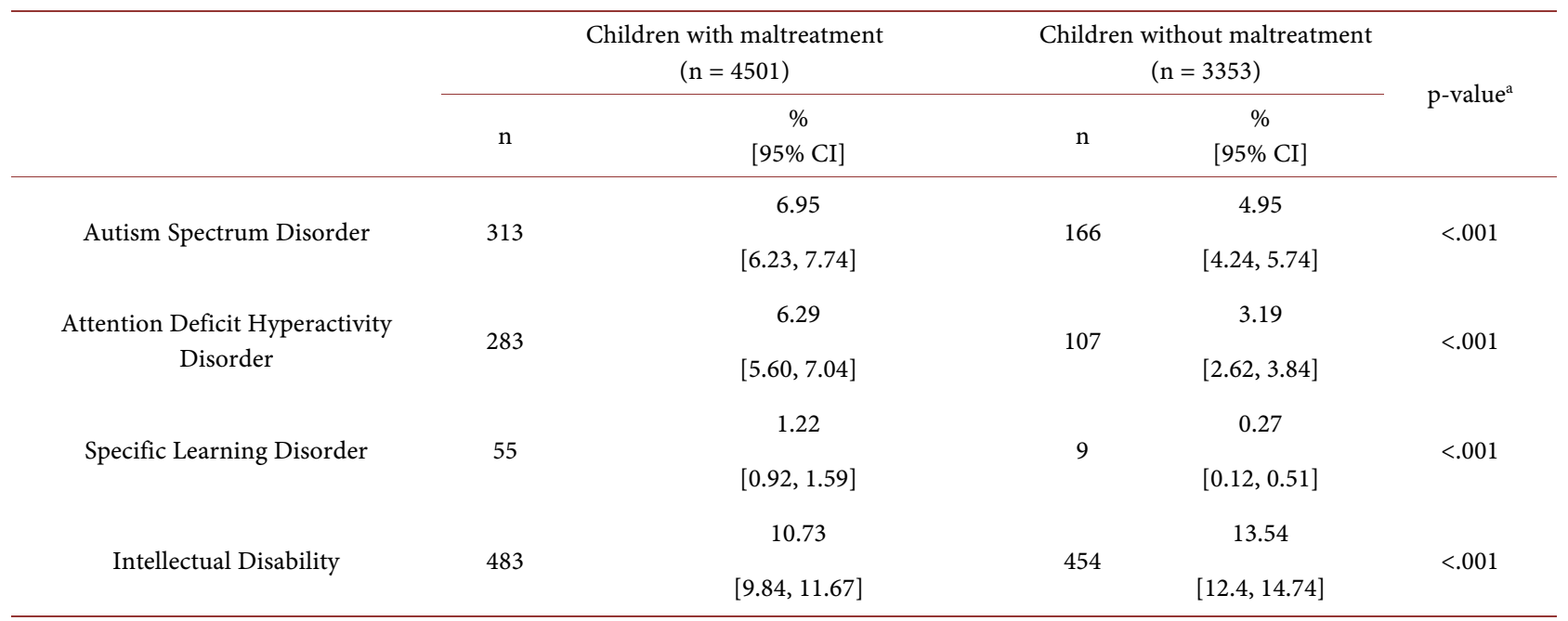

Note. $\mathrm{CI}=$ confidence interval. ${ }^{\text {a Estimated }}$ with chi-square tests by diagnostic status and experience of maltreatment.

Table 4. Logistic regression models of the prevalence of neurodevelopmental disorders.

\begin{tabular}{|c|c|c|c|c|c|c|c|c|}
\hline & \multicolumn{2}{|c|}{ ASD } & \multicolumn{2}{|c|}{ ADHD } & \multicolumn{2}{|c|}{ SLD } & \multicolumn{2}{|c|}{ ID } \\
\hline & $\begin{array}{c}\text { Odds ratio } \\
{[95 \% \mathrm{CI}]}\end{array}$ & $\mathrm{p}$-value ${ }^{\mathrm{a}}$ & $\begin{array}{c}\text { Odds ratio } \\
{[95 \% \mathrm{CI}]}\end{array}$ & $\mathrm{p}$-value ${ }^{\mathrm{a}}$ & $\begin{array}{c}\text { Odds ratio } \\
{[95 \% \mathrm{CI}]}\end{array}$ & $\mathrm{p}$-value ${ }^{\mathrm{a}}$ & $\begin{array}{c}\text { Odds ratio } \\
{[95 \% \mathrm{CI}]}\end{array}$ & $\mathrm{p}$-value ${ }^{\mathrm{a}}$ \\
\hline \multicolumn{9}{|c|}{ Experience of maltreatment ${ }^{\mathrm{b}}$} \\
\hline Yes & $\begin{array}{c}1.43 \\
{[1.18,1.74]}\end{array}$ & $<.001$ & $\begin{array}{c}2.04 \\
{[1.62,2.55]}\end{array}$ & $<.001$ & $\begin{array}{c}4.60 \\
{[2.27,9.31]}\end{array}$ & $<.001$ & $\begin{array}{c}0.77 \\
{[0.67,0.88]}\end{array}$ & $<.001$ \\
\hline
\end{tabular}




\section{Continued}

\begin{tabular}{|c|c|c|c|c|c|c|c|c|}
\hline Male & $\begin{array}{c}2.13 \\
{[1.74,2.61]}\end{array}$ & $<.001$ & $\begin{array}{c}3.03 \\
{[2.38,3.85]}\end{array}$ & $<.001$ & $\begin{array}{c}2.19 \\
{[1.27,3.89]}\end{array}$ & .005 & $\begin{array}{c}1.09 \\
{[0.95,1.25]}\end{array}$ & .228 \\
\hline \multicolumn{9}{|l|}{ Age group $^{\mathrm{d}}$} \\
\hline Preschool & $\begin{array}{c}0.48 \\
{[0.34,0.66]}\end{array}$ & $<.001$ & $\begin{array}{c}0.19 \\
{[0.11,0.31]}\end{array}$ & $<.001$ & $\begin{array}{c}0.28 \\
{[0.07,0.82]}\end{array}$ & .022 & $\begin{array}{c}0.60 \\
{[0.47,0.77]}\end{array}$ & $<.001$ \\
\hline Junior high school & $\begin{array}{c}0.97 \\
{[0.77,1.22]}\end{array}$ & .770 & $\begin{array}{c}1.08 \\
{[0.86,1.36]}\end{array}$ & .518 & $\begin{array}{c}1.00 \\
{[0.54,1.85]}\end{array}$ & .990 & $\begin{array}{c}1.24 \\
{[1.04,1.48]}\end{array}$ & .017 \\
\hline High school & $\begin{array}{c}0.92 \\
{[0.71,1.16]}\end{array}$ & .459 & $\begin{array}{c}0.50 \\
{[0.37,0.68]}\end{array}$ & $<.001$ & $\begin{array}{c}1.22 \\
{[0.67,2.23]}\end{array}$ & .522 & $\begin{array}{c}1.65 \\
{[1.39,1.96]}\end{array}$ & $<.001$ \\
\hline
\end{tabular}

Note. ASD = Autism spectrum disorder; ADHD = Attention deficit hyperactivity disorder; SLD = Specific learning disorder; ID = Intellectual disability; CI

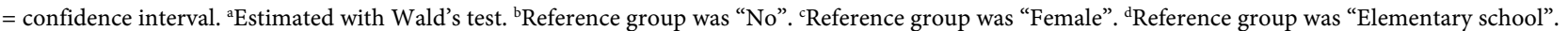

maltreatment. Whereas, only ID had opposite tendencies, OR $=0.77,95 \% \mathrm{CI}$ $[0.67,0.88], p<.001$.

Child gender difference was significant in 3 disorders, but not significant in $\mathrm{ID}, \mathrm{OR}=1.09,95 \%$ CI $[0.95,1.25], p=.228$. These indicated that the prevalence of those disorders was two times or higher for boys than girls.

The association between age groups and prevalence were disparate in each types of disorders. In case of ASD and SLD, the ratio of preschool children was significantly lower than elementary school. The ORs of other comparisons in those disorders were not significant. In ADHD, the preschool and high school age groups were less likely to have diagnosis than elementary school. In ID, the prevalence in preschool children were lower, $\mathrm{OR}=0.60,95 \% \mathrm{CI}[0.47,0.77], p$ $<.001$, and the others were higher than elementary school: junior high school, $\mathrm{OR}=1.27,95 \%$ CI $[1.04,1.48], p=.017$, and high school, OR $=1.65,95 \% \mathrm{CI}$ $[1.39,1.96], p<.001$.

\section{Discussion}

\subsection{Overall Prevalence of Neurodevelopmental Disorders}

The present study shows that $24 \%$ of children in CHs had substantial diagnoses of neurodevelopmental disorders. This result indicated that children in Japanese $\mathrm{CHs}$ were at a high-risk group of neurodevelopmental disorders and associated behavioral and mental health problems.

\subsection{Characteristics of Specific Disorders}

ID was the most common neurodevelopmental disorder in CHs. The ID prevalence in all Japanese children under 18 years old was reported as $0.78 \%$ (Cabinet Office Japan, 2015), and worldwide prevalence throughout childhood and adolescence was estimated as $1.83 \%$ (Maulik, Mascarenhas, Mathers, Dua, \& Saxena, 2011). Whereas, children in this study showed the rate at $11.93 \%$, that was approximately 6 to 15 times higher than the general proportion. 
It is noteworthy that developmental difference of ID risks was observed, in contrast to nonsignificant gender effect. Our ID prevalence in CHs had significantly increased as the children grew up until high school age. This finding was contrasted with the work by Harris (2006), who pointed out that general prevalence of ID increases from preschool to elementary school age, because of expectations for their school performance. Additionally, our results were also contrastive to the previous studies of residential care which also suggested that children assessed at early age tends to have larger IQ delays (van Ijzendoorn et al., 2008). In this respect, this insight was mainly evaluated from samples of younger children aged between 0 to 12 years, and the data including adolescents as in the present study were limited. There have been several studies of children with a wide age range in else types of out-of-home care. The outcomes from a study of Swedish foster children noted that they had lower cognitive and educational performance in late teens (Vinnerljung \& Hjern, 2011). A meta-analyses that largely used Western country's data revealed the IQ difference between adopted and unadopted children was significantly larger in adulthood (van Ijzendoorn, Juffer, \& Poelhuis, 2005). Considering these findings, our results of the developmental trajectory in ID appears to correspond to those of foster care and adoption in Western countries. A possible explanation of this similarity in different care types is that they had similar trends of child placement because both $\mathrm{CHs}$ in Japan, and foster care and adoption in Western countries were the most common in each nation.

The next highest prevalence in our samples was ASD. Recent studies reported that the general ASD ratio in Japan was 1.83\% (Kawamura, Takahashi, \& Ishii, 2008), and in U.S. was 2.24\% (Zablotsky, Black, Maenner, Schieve, \& Blumberg, 2015). We found the ASD prevalence in CHs was $6.10 \%$, which was higher than both of those. Related to ASD diagnosis, it is recognized that some children who experienced severe institutional deprivation in early life show autistic features, called "Quasi-Autism (Q-A)" (Rutter et al., 1999). There is a possibility that our ASD samples had included a few Q-A children. In this respect, Rutter et al. also pointed out that Q-A features were major in 4 year olds and tended to decrease in 6 year olds. Contrary to this pattern, the analysis between age groups found that our ASD prevalence in preschool aged children were lower than the older children. This distinction in developmental patterns suggests that samples in the current study could exclude Q-A children from ASD diagnosis, and children in Japanese CHs have a low probability to show Q-A features compared to institutions in other countries.

The ADHD prevalence was $4.97 \%$ in CHs. This ratio was quite compatible with the $5 \%$ that was estimated as the worldwide prevalence (American Psychiatric Association, 2013). Contrary to the predictions, this finding implies that the ADHD risk was similar in both the $\mathrm{CHs}$ and general children, and the ADHD risk ranged below the ASD risk of children in Japanese CHs. Among the age groups, ADHD was major in elementary and junior high school, and minor in preschool and high school. The low rate in high school support the previous re- 
search that found ADHD decreases as children age (Langberg et al., 2008). However, the result of preschool was contrary to a Japanese population study that suggested that the general rate of preschool ADHD was 5.8\% (Nomura et al., 2014). A possible contributor to this could be the complex relationships between ADHD and child maltreatment. It has been well known in Japanese professions that the symptoms of attachment disruptions caused by child abuse have commonality with ADHD (Mizuno et al., 2015). Consequently, there is a possibility that a definitive diagnosis in preschool age for $\mathrm{CH}$ children who persist in the symptoms associated with ADHD or attachment disruptions might be postponed until school age, in order to avoid the risk of misdiagnosis.

The SLD ratio in this study ranged comparatively low $(0.81 \%)$. The prevalence of dyslexia that is regarded as the most common manifestation in SLD suspected $3.8 \%$ in second grade of Japanese elementary school (Ogino et al., 2011). The groups showing higher ratios in the samples were elementary and high school boys $(1.24 \%)$, although this percentage was less than half of above the general ratio or previous scores of children in welfare systems (DosReis, Zito, Safer, \& Soeken, 2001; Lightfoot, Hill, \& LaLiberte, 2011). These signify the SLD risk of children in Japanese CHs was substantially lower than other disorders.

\subsection{Association with Child Maltreatment}

We focused on the experience of child maltreatment prior to the placement as the factor related to diagnoses of neurodevelopmental disorders. The results among 3 disorders of ASD, ADHD, and SLD were consistent with the previous studies that found child maltreatment significantly predicted the risk of these disorders. Surprisingly, we found that the prevalence of ID with maltreated children was less than without maltreatment, showing an opposite trend to other diagnoses. It has been claimed that delayed intellectual development would be caused by child maltreatment as well as increased risk of maltreatment, similar with other disorders (Sullivan \& Knutson, 1998). This gap might be understood by the child welfare system in Japan. There are different forms of residential facilities that provide specialized care and treatment for disabled children, besides the $\mathrm{CH}$ that provides usual rearing. Children with comparatively severe disorders with the need of out-of-home care were usually placed to these special facilities which are also factored into the ratio of maltreated children. Because maltreated children with more severe intellectual delay tend to be placed into other types of care, there is a possibility that maltreated ID numbers in this study were decreased. This hypothesis should be examined by further work including data from specialized facilities.

\subsection{Limitations}

This study revealed the current state of $\mathrm{CHs}$ in Japan that differed from previous studies in Western countries, however there were several limitations. The method to identify diagnoses relied on child records in the facilities due to the col- 
lection of data from large samples. Further research is required to include the diagnostic information which was ascertained using the standardized assessment tools, and the evaluation of severity levels of each symptom and intellectual development. Moreover, this study did not obtain the detailed developmental history including types of maltreatment, duration in care, placement stabilities, and so on. Another limitation is that our study used a cross-sectional design, thus the longitudinal or cohort study to analyze the developmental change should be conducted.

\section{Conclusion}

In conclusion, our results demonstrated high risks of neurodevelopmental disorders in Japanese CHs. Especially, the high prevalence of ID and ASD was estimated as unique from previous findings. These results highlight the necessity for children in $\mathrm{CHs}$ to obtain a continuous assessment of neurodevelopmental features and tailored care for individual traits as well as the consideration for outcomes of child maltreatment. Currently, Japanese child care system has been promoting the advancement of foster care and the reduction of care size in each $\mathrm{CH}$. When discussing to improve the child care form in Japan, it is necessary to create an environment which is appropriate for children with neurodevelopmental features.

\section{Acknowledgements}

This work was supported by a grant from the JSPS KAKENHI Grant Numbers 25870497, 17K13875.

\section{References}

American Psychiatric Association (2000). Diagnostic and Statistical Manual of Mental Disorders: DSM-IV-TR. Washington DC: American Psychiatric Association.

American Psychiatric Association (2013). Diagnostic and Statistical Manual of Mental Disorders: DSM-5. Arlington, VA: American Psychiatric Association. https://doi.org/10.1176/appi.books.9780890425596

Barth, R. P. (2005). Residential Care: From Here to Eternity. International Journal of Social Welfare, 14, 158-162. https://doi.org/10.1111/j.1468-2397.2005.00355.x

Berger, L. M., Bruch, S. K., Johnson, E. I., James, S., \& Rubin, D. (2009). Estimating the "Impact" of Out-of-Home Placement on Child Well-Being: Approaching the Problem of Selection bias. Child Development, 80, 1856-1876. https://doi.org/10.1111/j.1467-8624.2009.01372.x

Bronsard, G., Alessandrini, M., Fond, G., Loundou, A., Auquier, P., Tordjman, S., \& Boyer, L. (2016). The Prevalence of Mental Disorders among Children and Adolescents in the Child Welfare System. Medicine, 95, e2622. https://doi.org/10.1097/MD.0000000000002622

Bronsard, G., Lançon, C., Loundou, A., Auquier, P., Rufo, M., \& Siméoni, M.-C. (2011). Prevalence Rate of DSM Mental Disorders among Adolescents Living in Residential Group Homes of the French Child Welfare System. Children and Youth Services Review, 33, 1886-1890. https://doi.org/10.1016/j.childyouth.2011.05.014 
Burns, B. J., Phillips, S. D., Wagner, H. R., Barth, R. P., Kolko, D. J., Campbell, Y., \& Landsverk, J. (2004). Mental Health Need and Access to Mental Health Services by Youths Involved with Child Welfare: A National Survey. Journal of the American Academy of Child \& Adolescent Psychiatry, 43, 960-970. https://doi.org/10.1097/01.chi.0000127590.95585.65

Cabinet Office Japan (2015). Annual Report on Government Measures for Persons with Disabilities (Summary) 2015. http://www8.cao.go.jp/shougai/english/annualreport/2015/index-pdf.html

Costello, E. J., Mustillo, S., Erkanli, A., Keeler, G., \& Angold, A. (2003). Prevalence and Development of Psychiatric Disorders in Childhood and Adolescence. Archives of General Psychiatry, 60, 837-844. https://doi.org/10.1001/archpsyc.60.8.837

Courtney, M. E., Dolev, T., \& Gillian, R. (2009). Looking Backward to See Forward Clearly: A Cross-National Perspective on Residential Care. In M. E. Courtney \& D. Iwaniec (Eds.), Residential Care of Children: Comparative Perspectives (pp. 191-208). Oxford University Press.

https://doi.org/10.1093/acprof:oso/9780195309188.003.0012

DosReis, S., Zito, J. M., Safer, D. J., \& Soeken, K. L. (2001). Mental Health Services for Youths in Foster Care and Disabled Youths. American Journal of Public Health, 91, 1094-1099. https://doi.org/10.2105/AJPH.91.7.1094

Equal Employment, Children and Families Bureau (2015). Jidou yougo shistu nyuusyo jidou tou tyousa kekka [Results of Survey of Children in Residential Care Institutions]. http://www.mhlw.go.jp/file/04-Houdouhappyou-11905000-Koyoukintoujidoukateikyo ku-Kateifukushika/0000071184.pdf

Ford, T., Vostanis, P., Meltzer, H., \& Goodman, R. (2007). Psychiatric Disorder among British Children Looked after by Local Authorities: Comparison with Children Living in Private Households. The British Journal of Psychiatry, 190, 319-325. https://doi.org/10.1192/bjp.bp.106.025023

Fox, N. A., Almas, A. N., Degnan, K. A., Nelson, C. A., \& Zeanah, C. H. (2011). The Effects of Severe Psychosocial Deprivation and Foster Care Intervention on Cognitive Development at 8 Years of Age: Findings from the Bucharest Early Intervention Project. Journal of Child Psychology and Psychiatry and Allied Disciplines, 52, 919-928. https://doi.org/10.1111/j.1469-7610.2010.02355.x

Harris, J. C. (2006). Intellectual Disability: Understanding Its Development, Causes, Classification, Evaluation, and Treatment. New York: Oxford University Press.

Jozefiak, T., Kayed, N. S., Rimehaug, T., Wormdal, A. K., Brubakk, A. M., \& Wichstrøm, L. (2016). Prevalence and Comorbidity of Mental Disorders among Adolescents Living in Residential Youth Care. European Child \& Adolescent Psychiatry, 25, 33-47. https://doi.org/10.1007/s00787-015-0700-x

Kawamura, Y., Takahashi, O., \& Ishii, T. (2008). Reevaluating the Incidence of Pervasive Developmental Disorders: Impact of Elevated Rates of Detection through Implementation of an Integrated System of Screening in Toyota, Japan. Psychiatry and Clinical Neurosciences, 62, 152-159. https://doi.org/10.1111/j.1440-1819.2008.01748.x

Langberg, J. M., Epstein, J. N., Altaye, M., Molina, B. S. G., Arnold, L. E., \& Vitiello, B. (2008). The Transition to Middle School Is Associated with Changes in the Developmental Trajectory of ADHD Symptomatology in Young Adolescents with ADHD. Journal of Clinical Child \& Adolescent Psychology, 37, 651-663. https://doi.org/10.1080/15374410802148095

Lehmann, S., Havik, O. E., Havik, T., \& Heiervang, E. R. (2013). Mental Disorders in Foster Children: A Study of Prevalence, Comorbidity and Risk Factors. Child and 
Adolescent Psychiatry and Mental Health, 7, 39. https://doi.org/10.1186/1753-2000-7-39

Lightfoot, E., Hill, K., \& LaLiberte, T. (2011). Prevalence of Children with Disabilities in the Child Welfare System and Out of Home Placement: An Examination of Administrative Records. Children and Youth Services Review, 33, 2069-2075.

https://doi.org/10.1016/j.childyouth.2011.02.019

Maulik, P. K., Mascarenhas, M. N., Mathers, C. D., Dua, T., \& Saxena, S. (2011). Prevalence of Intellectual Disability: A Meta-Analysis of Population-Based Studies. Research in Developmental Disabilities, 32, 419-436. https://doi.org/10.1016/j.ridd.2010.12.018

McCann, J. B., James, A., Wilson, S., \& Dunn, G. (1996). Prevalence of Psychiatric Disorders in Young People in the Care System. BMJ, 313, 1529-1530. https://doi.org/10.1136/bmj.313.7071.1529

McGovern, C. W., \& Sigman, M. (2005). Continuity and Change from Early Childhood to Adolescence in Autism. Journal of Child Psychology and Psychiatry and Allied Disciplines, 46, 401-408. https://doi.org/10.1111/j.1469-7610.2004.00361.x

McMillen, J. C., Zima, B. T., Scott, L. D., Auslander, W. F., Munson, M. R., Ollie, M. T., \& Spitznagel, E. L. (2005). Prevalence of Psychiatric Disorders among Older Youths in the Foster Care System. Journal of the American Academy of Child and Adolescent Psychiatry, 44, 88-95.

Meltzer, H., Gatward, R., Corbin, T., Goodman, R., \& Ford, T. (2003). The mental Health of Young People Looked after by Local Authorities in England. London, England: Office for National Statistics. https://doi.org/10.1037/e616412007-001

Ministry of Health, Labour and Welfare (2016). Syakai teki yougo no suihin ni mukete [Toward Promotion of Social Care for Children]. http://www.mhlw.go.jp/file/06-Seisakujouhou-11900000-Koyoukintoujidoukateikyoku 10000143116.pdf

Mizuno, K., Takiguchi, S., Yamazaki, M., Asano, M., Kato, S., Kuriyama, K. et al. (2015). Impaired Neural Reward Processing in Children and Adolescents with Reactive Attachment Disorder: A Pilot Study. Asian Journal of Psychiatry, 17, 89-93. https://doi.org/10.1016/j.ajp.2015.08.002

Nomura, K., Okada, K., Noujima, Y., Kojima, S., Mori, Y., Amano, M. et al. (2014). A Clinical Study of Attention-Deficit/Hyperactivity Disorder in Preschool Children-Prevalence and Differential Diagnoses. Brain and Development, 36, 778-785. https://doi.org/10.1016/j.braindev.2013.11.004

Ogino, T., Takahashi, Y., Hanafusa, K., Watanabe, K., Morooka, T., Takeuchi, A. et al. (2011). Reading Skills of Japanese Second-Graders. Pediatrics International, 53, 309-314. https://doi.org/10.1111/j.1442-200X.2010.03229.x

Ohara, T., \& Matsuura, N. (2016). The Characteristics of Delinquent Behavior and Predictive Factors in Japanese Children's Homes. Children and Youth Services Review, 61, 159-164. https://doi.org/10.1016/j.childyouth.2015.12.024

Pollak, S. D., Nelson, C. A., Schlaak, M. F., Roeber, B. J., Wewerka, S. S., Wiik, K. L. et al. (2010). Neurodevelopmental Effects of Early Deprivation in Postinstitutionalized Children. Child Development, 81, 224-236. https://doi.org/10.1111/j.1467-8624.2009.01391.x

R Core Team (2016). R: A Language and Environment for Statistical Computing. Vienna, Austria: R Foundation for Statistical Computing. https://www.r-project.org/

Rutter, M., Andersen-Wood, L., Beckett, C., Bredenkamp, D., Castle, J., Groothues, C. et al. (1999). Quasi-Autistic Patterns Following Severe Early Global Privation. Journal of Child Psychology and Psychiatry, 40, 537-549. https://doi.org/10.1111/1469-7610.00472 
Schmid, M., Goldbeck, L., Nuetzel, J., \& Fegert, J. M. (2008). Prevalence of Mental Disorders among Adolescents in German Youth Welfare Institutions. Child and Adolescent Psychiatry and Mental Health, 2, 2. https://doi.org/10.1186/1753-2000-2-2

Sullivan, P. M., \& Knutson, J. F. (1998). The Association between Child Maltreatment and Disabilities in a Hospital-Based Epidemiological Study. Child Abuse \& Neglect, 22, 271-288. https://doi.org/10.1016/S0145-2134(97)00175-0

van Ijzendoorn, M. H., Juffer, F., \& Poelhuis, C. W. K. (2005). Adoption and Cognitive Development: A Meta-Analytic Comparison of Adopted and Nonadopted Children's IQ and School Performance. Psychological Bulletin, 131, 301-316.

https://doi.org/10.1037/0033-2909.131.2.301

van Ijzendoorn, M. H., Luijk, M. P. C. M., \& Juffer, F. (2008). IQ of Children Growing Up in Children's Homes: A Meta-Analysis on IQ Delays in Orphanages. Merrill-Palmer Quarterly, 54, 341-366. https://doi.org/10.1353/mpq.0.0002

Vinnerljung, B., \& Hjern, A. (2011). Cognitive, Educational and Self-Support Outcomes of Long-Term Foster Care versus Adoption. A Swedish National Cohort Study. Children and Youth Services Review, 33, 1902-1910.

https://doi.org/10.1016/j.childyouth.2011.05.016

Zablotsky, B., Black, L. I., Maenner, M. J., Schieve, L. A., \& Blumberg, S. J. (2015). Estimated Prevalence of Autism and Other Developmental Disabilities Following Questionnaire Changes in the 2014 National Health Interview Survey. National Health Statistics Reports, No. 87, 1-20. 